\title{
Structural Factors of Annonaceous Acetogenins and Their Semisynthetic Analogues Related with the Toxicity on Spodoptera frugiperda
}

\author{
Lilian Di Toto Blessing1, Florencia Budeguer¹, Juan Ramos ${ }^{4}$, Alicia Bardón¹,3, Sonia Diaz², \\ Margarita Brovetto ${ }^{2}$, Gustavo Seoane ${ }^{2}$, Adriana Neske ${ }^{1 *}$ \\ ${ }^{1}$ Instituto de Química Orgánica, Facultad de Bioquímica, Química y Farmacia, Universidad Nacional de Tucumán, \\ Ayacucho, Argentina \\ ${ }^{2}$ Instituto de Química Física, Facultad de Bioquímica, Química y Farmacia, Universidad Nacional de Tucumán, \\ Ayacucho, Argentina \\ ${ }^{3}$ INQUINOA-CONICET, Tucumán, Argentina \\ ${ }^{4}$ Dpto de Química Orgánica, Fac de Química, UdelaR, Montevideo, Uruguay \\ Email: aneske@fbqf.unt.edu.ar
}

Received 2 March 2015; accepted 22 May 2015; published 26 May 2015

Copyright (C) 2015 by authors and Scientific Research Publishing Inc.

This work is licensed under the Creative Commons Attribution International License (CC BY).

http://creativecommons.org/licenses/by/4.0/

(c) (i) Open Access

\begin{abstract}
Toxic and nutritional effects of annonaceous acetogenins and their semisynthetic analogues on Spodoptera frugiperda were evaluated. Structural modification of the natural ACG, blocking the OH flanking THF with MOM, allowed us to suggest the mode of action of ACG in the membrane. Our study emphasizes the role of the flanking $\mathrm{OH}$ and acetyl groups of THF with the membrane hydrophilic polar head groups. They are essential structural factors in the ACG that facilitate the intermolecular interaction that dehydrates the membrane and makes it potentially toxic against Spodoptera frugiperda.
\end{abstract}

Keywords

Annonaceous Acetogenins, Polyphagous Lepidopteran, Toxicity, Nutritional Alterations

\section{Introduction}

Annonaceous acetogenins (ACG) are a large group of natural products exclusively isolated from the Annona${ }^{*}$ Corresponding author.

How to cite this paper: Di Toto Blessing, L., et al. (2015) Structural Factors of Annonaceous Acetogenins and Their Semisynthetic Analogues Related with the Toxicity on Spodoptera frugiperda. Journal of Agricultural Chemistry and Environment, 4, 56-61. http://dx.doi.org/10.4236/jacen.2015.42006 
ceae family. They are characterized by a common skeleton usually formed by 35 to 37 carbon atoms, which have a long alkyl chain terminal end that usually exhibits a $\gamma$-methyl- $\gamma$-lactone, $\alpha, \beta$-unsaturated. The hydrocarbon chain attached to position 2 lactone may have one, two, or more rarely, three-ring tetrahydrofuran (THF) and oxygenated functions and double bonds.

Synthetic analogues, such as the THF central rings of ACG and several structural modifications have been the subject of various studies in the literature [1] [2].

The most important effects of ACG have been described on cancer cell lines, especially those resistant to chemotherapy. Their cytotoxicity is due to the fact that they inhibit ATP synthesis at the mitochondrial complex I. Apparently, inhibition of the respiratory chain would be the most important mechanism through which ACG cause insect larval and pupal mortality. On other hand, Di Toto Blessing et al. (2012) suggested that mitochondrial Complex I inhibition was not the only mode of action of annonaceous acetogenins, since insecticidal action would be by the destabilization that occurred in the membrane due to dehydration around the phosphate groups caused by interaction with ACG and their synthetic analogues [3] [4].

In addition, the insecticidal properties of acetogenins against several key crop pests in different parts of the world have repeatedly been described [5]. Spodoptera frugiperda (J.E. Smith) is a polyphagous lepidopteran commonly called fall armyworm, a major pest in corn fields where it feeds on leaves, tassels and ears of corn [6]-[8]. It has become one of the most serious problems for corn crops in tropical and subtropical regions of Latin America for the important damages it produces. S. frugiperda displays a very wide host range with over 80 plants recorded, though grasses are preferred. Severe damages are particularly caused during its last two larval stages [9]-[12].

Previous results from our laboratory indicated that the natural ACG had larvicidal and pupal mortality effects on the corn pest, S. frugiperda (Lepidoptera: Noctuidae) [13]-[17]. Additionaly, treatment with R. occidentalis acetogenin fraction is environmentally selective and shows an excellent degree of selectivity towards beneficial insects minimizing the detrimental effects of pesticides on natural enemies, allowing their survival and sustainable control of pests [18]. Especially the seeds are a promising source of ACG that can be used as a prototype model and/or a biorational insecticide for the control of S. frugiperda. Furthermore, toxic effects of ACG have been reported for several species of insects, S. littoralis, Leptinotarsa decemlineata, Mizus persicae [5].

The aim of this work was to find a relationship of the insecticidal properties on S. frugiperda between natural ACG and their semisynthetic analogues. We first carried out the isolation of the mono and bis-THF ACG from Annona montana and A. cherimolia, and prepared their acetylated (OAc) and methoxy methylated (MOM) derivatives by chemical methods. ACG analogues were synthesized and characterized by spectroscopic techniques (IR, ${ }^{1} \mathrm{H}-\mathrm{NMR},{ }^{13} \mathrm{C}-\mathrm{NMR}$, and MS) [1].

For this purpose, we employed mono THF ACG with OH groups flanking the THF and its acetylated derivatives: annonacin (1), annonacin (3 OAc) (2), and annonacin (4 OAc) (3); bis-THF ACG adjacent with OH groups flanking the two THF and its acetylated derivatives: rolliniastatin-2 (4), rolliniastatin-2 (3 OAc) (5), itrabin (6), itrabin (3 OAc) (7), and its methoxy methylated derivative: itrabin (3 MOM) (8); as well as the semisynthetic analogue compounds 9-12 (Figure 1).

We evaluated the toxic effects produced by ACG and their semisynthetic analogues on S. frugiperda. Additionally, Consumption Index (CI), Growth (GR), and Efficiency in the Consumption Index (ECI) were also assessed.

\section{Experimental Analysis}

Plant material: Annona cherimolia seeds from “chirimoya” fruits were collected in Tucumán, Argentina. A. montana seeds from "sinini" fruits were collected in Santa Cruz de la Sierra, Bolivia.

ACG extraction and purification: The dried and powdered seeds of Annona cherimolia and A. montana were macerated with methanol. The methanolic extracts were evaporated and the residue partitioned in a mixture of $\mathrm{CHCl}_{3} / \mathrm{H}_{2} \mathrm{O}$ (1:1). The subextracts in chloroform and $\mathrm{H}_{2} \mathrm{O}$ were obtained by vacuum evaporation. The chloro-formic subextract was partitioned with a mixture of hexane/methanol (1:1). Annonacin (1) [19] (Figure 1), was isolated from $A$. montana methanolic subextract after treatment with semipreparative RP-HPLC with $\mathrm{MeOH} / \mathrm{H}_{2} \mathrm{O}$ (80:20). Rolliniastatin-2 (4) [20] and itrabin (6) [21] (Figure 1), were isolated from A. cherimolia methanolic subextract after treatment with semipreparative RP-HPLC with $\mathrm{MeOH} / \mathrm{H}_{2} \mathrm{O}$ (80:20). After exhausttively purified by RP-HPLC, the characterization was assessed by spectroscopic techniques (IR, ${ }^{1} \mathrm{H}-\mathrm{NMR}$, ${ }^{13} \mathrm{C}-\mathrm{NMR}$, and MS) as well as $\alpha_{\mathrm{D}}$ determination, in comparison with previously reported data [13]. Acetogenins 


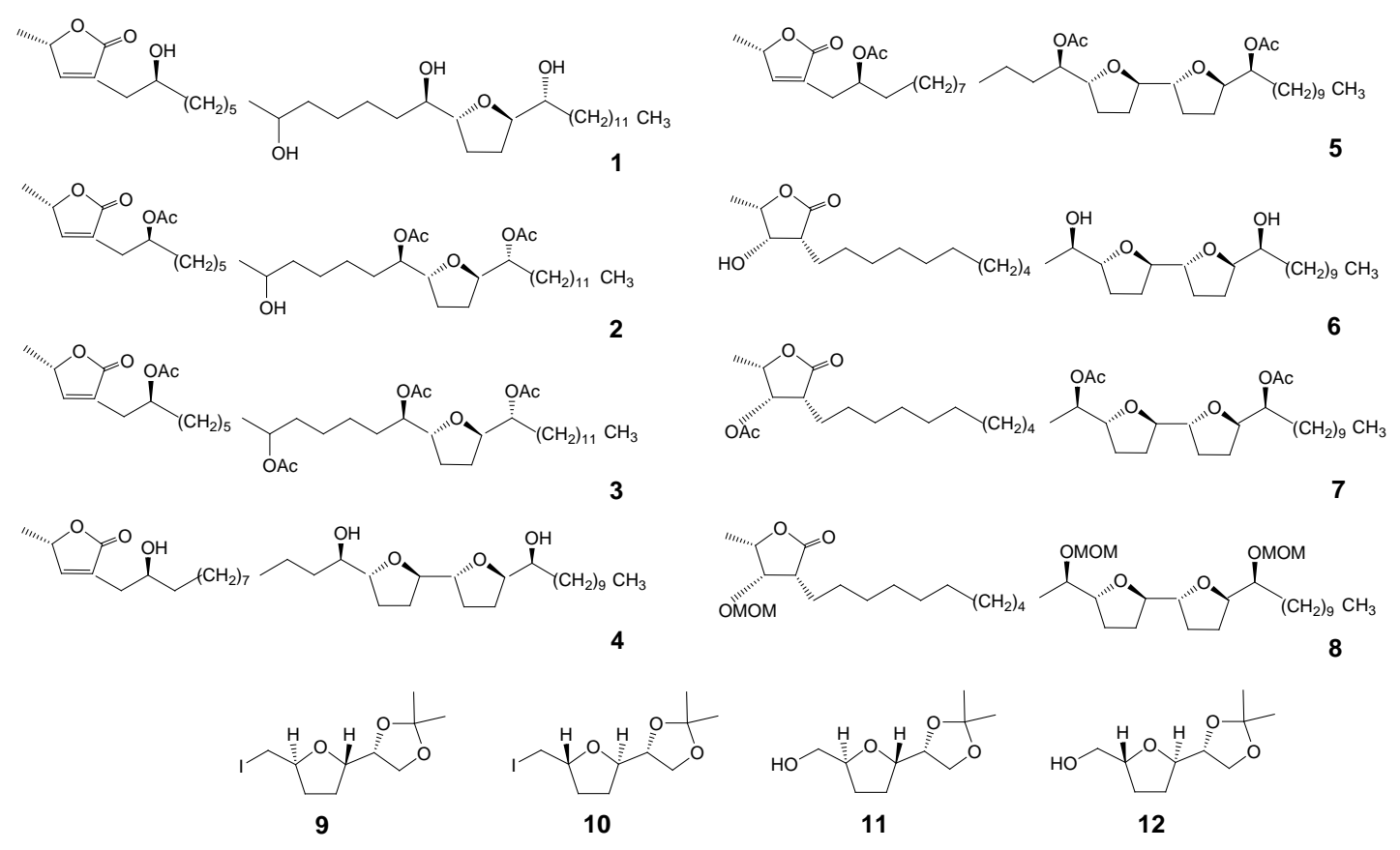

Figure 1. Annonaceous acetogenins and their semisynthetic analogues.

represent around $0.07 \%$ of the seed weight. The acetogenin fraction of the $R$. occidentalis methanol seed extract was selected for the present study.

Structurally modified ACG: Acetylated analogues, annonacin (3OAc) (2), annonacin (4OAc) (3), rolliniastatin-2 (3OAc) (5), and itrabin (3OAc) (7), were obtained by chemical acetylation with acetic anhydride at room temperature under a nitrogen atmosphere and with the addition of triethylamine. The residue obtained after solvent evaporation was chromatographed on silica gel. The compounds of interest were purified by column chromatography and identified by spectroscopic methods of high resolution NMR and MS.

Methoxy methylated derivative, itrabin (3MOM) (8) was obtained by adding $N, N$-diisopropylethylamine and methoxymethyl chloride to a solution of ACG $\mathbf{6}$ in dichloromethane under a nitrogen atmosphere. The reaction was followed by TLC until the formation of products. The residue obtained after solvent evaporation was chromatographed by flash column. The identification of the bis-THF ACG methoxy methylated 8, was achieved by comparison of spectroscopic data ${ }^{1} \mathrm{H}-\mathrm{NMR}$ and ${ }^{13} \mathrm{C}-\mathrm{NMR}$ with the sample of the original ACG 6.

THF semisynthetic analogues: The compounds 9, 10, 11, and 12 (Figure 1), were prepared by iodoetherification of chiral 4-alkenols obtained in four steps from 3-bromo-3,5-cyclohexadiene-1,2-diol. This chiral starting material was obtained by microbial dihydroxylation of bromobenzene, a powerful synthetic methodology for the enantioselective preparation of natural products. All THF synthetic analogues were purified by column chromatography on silica gel using hexane/ethyl acetate as eluant [1].

\subsection{Treatment Formulations}

Test solution: Natural ACG and their semisynthetic analogues solutions were prepared at $100 \mu \mathrm{g} / \mathrm{mL}$, all under the same conditions [7].

Test insects: S. frugiperda larvae were obtained from our laboratory population. The larval diet consisted of a mixture of yeast (3 g), bean boiled and milled (250 g), wheat germ (12.5 g), agar agar (12.5 g), ascorbic acid (1.5 g), methyl p-hydroxybenzoate (1.5 g), formaldehyde (4 mL of a $38 \%$ water solution), and water (500 mL) [7].

Toxicity test: The assays were recorded for treatments with all acetogenins $(100 \mu \mathrm{g} / \mathrm{mL})$ and control experiments. The nutritional indices were determinated by the Consumption Index (CI), Growth Rate (GR), and Efficiency in the Consumption Index (ECI). For comparison purposes, rates are expressed as a relationship between treatment and control; the latter are considered as $100 \%$. Values are expressed as $\left(\mathrm{GR}_{\mathrm{T}} / \mathrm{GR}_{\mathrm{C}}\right) 100 \%,\left(\mathrm{CI}_{\mathrm{T}} / \mathrm{CI}_{\mathrm{C}}\right)$ 
$100 \%$ and $\left(\mathrm{ECI}_{\mathrm{T}} / \mathrm{ECI}_{\mathrm{C}}\right) 100 \%$ in the tables [16]. Toxicity was determined by evaluating $S$. frugiperda larval mortality and emergency adults. The assays had 20 replicates for each product tested and the control.

\subsection{Statistical Analysis}

Results are reported as Mean \pm SD. Differences in the mean values were evaluated by analysis of variance (ANOVA). The Tukey test was used for all pair wise multiple comparisons of groups. In all statistical analysis $\mathrm{P}$ values $>0.05$ were considered not significant.

\section{Results and Discussion}

Toxicity of annonaceous acetogenins: The results obtained with the addition of $100 \mu \mathrm{g} / \mathrm{g}$ of all natural ACG (1, 4 and 6), acetylated derivatives (2, 3, 5 and 7), methoxy methylated derivative (8), and THF rings (9-12) to the artificial larval diet for $S$. frugiperda, indicated that there were no antifeedant effects $\left(\mathrm{FR}_{50} \sim 1\right)$ under assay conditions.

However, the intake of $\mathbf{1}, \mathbf{2}$ and $\mathbf{3}$ was toxic, producing significant larval mortality in the early stages (70\%, $75 \%$ and $60 \%$, respectively) and low adult emergence (30\%, 25\% and $40 \%$, respectively), as shown in Table 1 . The addition of compounds $\mathbf{1}, \mathbf{2}$ and $\mathbf{3}$ to the larval diet caused significant changes in nutritional indices compared to those of larvae fed the control diet. These compounds showed a significant percentage of consump- tion $\left(\mathrm{CI}_{\mathrm{T}} / \mathrm{CI}_{\mathrm{C}}=83 \%, 67 \%\right.$ and 97\%, respectively). Furthermore, compound 2 provoked a marked decrease in larval growth $\left(\mathrm{GR}_{\mathrm{T}} / \mathrm{GR}_{\mathrm{C}}=12 \%\right)$ and inefficiency in converting the absorbed nutrients into biomass $\left(\mathrm{ECI}_{\mathrm{T}} / \mathrm{ECI}_{\mathrm{C}}=18 \%\right)$ (Table 1).

The addition of $100 \mu \mathrm{g} / \mathrm{g}$ of natural ACG bis-THF $\mathbf{4}$ and $\mathbf{6}$, and their derivative analogues 5,7 and 8 to the artificial larval diet for $S$. frugiperda, indicated that there were no significant toxic effects and changes in nutritional index values under assay conditions. Treatment with $\mathbf{9}$ and $\mathbf{1 0}$ caused significant larval mortality in the early stages (100\% and 80\%, respectively). Compounds $\mathbf{1 1}$ and $\mathbf{1 2}$ showed low larval mortality (20\% and 15\%, respectively) and high adult emergence (80\% and $75 \%$, respectively). The addition of compound $\mathbf{1 0}$ to the larval diet showed significant difference in consumption $\left(\mathrm{CI}_{\mathrm{T}} / \mathrm{CI}_{\mathrm{C}}=53 \%\right)$, decrease in larval growth rate $\left(\mathrm{GR}_{\mathrm{T}} / \mathrm{GR}_{\mathrm{C}}=\right.$ $33 \%)$ and inefficiency in converting the absorbed nutrients into biomass $\left(\mathrm{ECI}_{\mathrm{T}} / \mathrm{ECI}_{\mathrm{C}}=62 \%\right)$. The results for 11 and 12 were less significant compared to control. Natural products like these, that exert their toxicity in early instar larvae before major damage has been produced, are important.

Table 1. Toxic effects and nutritional indices of ACG and their analogues on S. frugiperda.

\begin{tabular}{cccccc}
\hline Compounds & Larval mortality (\%) & Emergency adults (\%) & $\mathrm{CI}_{\mathrm{T}} / \mathrm{CI}_{\mathrm{C}}{ }^{\mathrm{a}}(\%)$ & $\mathrm{GR}_{\mathrm{T}} / \mathrm{GR}_{\mathrm{C}}{ }^{\mathrm{b}}(\%)$ & $\mathrm{ECI}_{\mathrm{T}} / \mathrm{ECI}_{\mathrm{C}}{ }^{\mathrm{c}}(\%)$ \\
\hline Control & 3 & 97 & - & - \\
$\mathbf{1}$ & 70 & 30 & $83 \pm 11$ & $68 \pm 12$ & $80 \pm 16$ \\
$\mathbf{2}$ & 75 & 25 & $67 \pm 10$ & $12 \pm 1$ & $18 \pm 5$ \\
$\mathbf{3}$ & 60 & 40 & $97 \pm 6$ & $92 \pm 15$ & $89 \pm 11$ \\
$\mathbf{4}$ & 5 & 95 & $95 \pm 8$ & $89 \pm 14$ & $94 \pm 11$ \\
$\mathbf{5}$ & 10 & 90 & $102 \pm 4$ & $98 \pm 17$ & $93 \pm 12$ \\
$\mathbf{6}$ & 5 & 95 & $95 \pm 4$ & $86 \pm 10$ & $91 \pm 9$ \\
$\mathbf{7}$ & 10 & 90 & $98 \pm 11$ & $98 \pm 11$ & $94 \pm 13$ \\
$\mathbf{8}$ & 5 & 95 & $95 \pm 2$ & $\mathrm{ND}$ & $100 \pm 5$ \\
$\mathbf{9}$ & 100 & $\mathrm{ND}$ & $\mathrm{ND}$ & $\mathrm{ND}$ \\
$\mathbf{1 0}$ & 80 & 20 & $53 \pm 1$ & $33 \pm 7$ & $62 \pm 13$ \\
$\mathbf{1 1}$ & 20 & 80 & $76 \pm 8$ & $74 \pm 11$ & $94 \pm 12$ \\
$\mathbf{1 2}$ & 15 & 85 & $72 \pm 11$ & $77 \pm 12$ & $97 \pm 17$ \\
\hline
\end{tabular}

${ }^{\mathrm{a}} \mathrm{CI}_{\mathrm{T}} / \mathrm{CI}_{\mathrm{C}}$ (Consumption Index); ${ }^{\mathrm{b}} \mathrm{GR}_{\mathrm{T}} / \mathrm{GR}_{\mathrm{C}}$ (Growth Rate); ${ }^{\mathrm{c}} \mathrm{ECI}_{\mathrm{T}} / \mathrm{ECI}_{\mathrm{C}}$ (Efficiency in the Consumption Index). For comparison purposes, rates of nutritional indices are expressed as a relationship between treatment and control. ND: Not determined. 
Short time ago, we investigated the mutagenic effects displayed by itrabin, as well as the phytotoxic and genotoxic action of squamocin and itrabin. Both compounds displayed slight phytotoxic and genotoxic effects on roots of Allium cepa at $2.5 \mu \mathrm{g} / \mathrm{mL}$ though no mutagenic effects were detected at $0.25,0.5$ and $2.5 \mu \mathrm{g} / \mathrm{mL}$ on Salmonella typhimurium strains TA98 and TA100 [15].

Recently, we observed the behavior in artificial membrane of POPC for mono THF ACG 1, 2 and 3, which could explain their insecticidal power on S. frugiperda, being the triacetylated 2 ACG the most toxic. The position and the amount of acetyl groups along the hydrocarbon chain had a significant effect on the activity, being three acetyl the optimal number [22]. The results obtained for natural and acetylated mono THF ACG 1, 2 and $\mathbf{3}$, showed that the dehydration that occurred in the membrane by their interaction led to destabilization and this would be the main cause by which the ACG produce the mortality of $S$. frugiperda [17].

Structural modification of the natural ACG, blocking the OH flanking THF, allowed us to suggest the mode of action of the ACG in the membrane. In this sense, we suggest that the capacity-donor hydrogen bonding of the hydroxy group acts as a hydrophilic anchor on the surface of the liposomal membrane and this result would explain the biological activity that ACG display. We conclude that the $\mathrm{OH}$ groups and/or $\mathrm{OCOCH}_{3}$ flanking the THF are essential structural factors for the intermolecular interaction with the hydrophilic polar head groups of the membrane. We suggest that this intermolecular interaction is the mechanism by which the ACG produce dehydration of the membrane and may then enhance bioactivity by restricting the location, conformation and orientation of the ACG.

These results enhance the understanding of the action mechanism of acetogenins in the membrane environment and the essential structural factors in the ACG, which makes it potentially toxic against Spodoptera frugiperda.

\section{Acknowledgements}

This work was supported by grants from Consejo de Investigaciones de la Universidad Nacional de Tucumán (CIUNT) and Concejo Nacional de Investigaciones Científicas y Técnicas (CONICET), República Argentina.

\section{References}

[1] Ramos, J.C., Brovetto, M. and Seoane, G. (2013) Chemoenzymatic Synthesisof Trans-Tetrahydrofuran Cores of Annonaceous Acetogenins from Bromobenzene. Organic Letters, 15, 1982-1985. http://dx.doi.org/10.1021/ol400650v

[2] Brown, R.C.D. and Suprr, I.B. (2010) Total Synthesis of Annonaceous Acetogenins Belonging to the Non-Adjacent Bis-THF and Non-Adjacent THF-THP Sub-Classes. Molecules, 15, 460-501. http://dx.doi.org/10.3390/molecules15010460

[3] Barrachina, I., Neske, A., Granell, S., Bermejo, A., Chahaboune, N., El Aouad, N., Álvarez Colom, O., Bardón, A. and Zafra-Polo, M.C. (2004) Tucumanin, a $\beta$-Hydroxy- $\gamma$-lactone bistetrahydrofuranic acetogenin from Annona cherimolia, Is a Potent Inhibitor of Mitochondrial Complex I. Planta Medica, 70, 866-868. http://dx.doi.org/10.1055/s-2004-827237

[4] Álvarez Colom, O., Neske, A., Chahaboune, N., Zafra-Polo, M.C. and Bardón, A. (2009) Tucupentol, a Novel MonoTetrahydrofuranic Acetogenin from Annona montana, as a Potent Inhibitor of Mitochondrial Complex I. Chemistry and Biodiversity, 6, 335-340. http://dx.doi.org/10.1002/cbdv.200800102

[5] Guadaño, A., Gutiérrez, C., de La Peña, E., Cortes, D. and González-Coloma, A. (2000) Insecticidal and Mutagenic Evaluation of Two Annonaceous Acetogenins. Journal of Natural Products, 63, 773-776. http://dx.doi.org/10.1021/np990328+

[6] Marenco, R.J., Foster, R.E. and Sanchez, C.A. (1992) Sweet Corn Response to Fall Armyworm (Lepidoptera: Noctuidae) Damage during Vegetative Growth. Journal of Economic Entomology, 85, 1285-1292. http://dx.doi.org/10.1093/jee/85.4.1285

[7] Kumar, H. and Mihn, J.A. (2002) Fall Armyworm (Lepidoptera: Noctuidae), Southwestern Corn Borer (Lepidoptera: Pyralidae) and Sugarcane Borer (Lepidoptera: Pyralidae) Damage and Grain Yield of Four Maize Hybrids in Relation to Four Tillage Systems. Crop Protection, 21, 121-128. http://dx.doi.org/10.1016/S0261-2194(01)00071-0

[8] Clavijo, S. and Pérez Greiner, G. (2000) Insectos plagas del maíz (sección 2). In: Fontana Nieves, H. and González Narváez, C., Eds., Protección y sanidad vegetal (capítulo 6), Fundación Polar, Caracas, 345-361.

[9] Murillo, A. (1991) Distribución, importancia y manejo del complejo Spodoptera en Colombia. In: Zuluaga, J.L. and Muñoz, G., Eds., Memorias Seminario Spodoptera frugiperda (El gusano cogollero) en sorgo, maíz y otros cultivos, Calí, Colombia, 15-23. 
[10] Sparks, A.N. (1979) A Review of the Biology of the Fall Armyworm. The Florida Entomologist, 62, 82-87. http://dx.doi.org/10.2307/3494083

[11] Murúa, M.G., Virla, E.G. and Defagó, V. (2003) Evaluación de cuatro dietas artificiales para la cría de Spodoptera frugiperda (Lep.: Noctuidae) destinada a mantener poblaciones experimentales de himenópteros parasitoides. Boletín de Sanidad Vegetal de Plagas, 29, 43-51.

[12] Murúa, M.G. and Virla, E. (2004) Population Parameters of Spodoptera frugiperda (Smith) (Lep.: Noctuidae) Fed on Corn and Two Predominant Grasess in Tucumán (Argentina). Acta Zoológica Mexicana, 20, 199-210.

[13] Álvarez Colom, O., Neske, A., Popich, S. and Bardón, A. (2007) Toxic Effects of Annonaceous Acetogenins from Annona cherimolia (Magnoliales: Annonaceae) on Spodoptera frugiperda (Lepidoptera: Noctuidae). Journal of Pest Science, 80, 63-67. http://dx.doi.org/10.1007/s10340-006-0149-2

[14] Álvarez Colom, O., Barrachina, I., Ayala Mingol, I., González Mas, M.C., Moya Sanz, P., Neske, A. and Bardón, A. (2008) Toxic Effects of Annonaceous Acetogenins on Oncopeltus fasciatus. Journal of Pest Science, 81, 85-89. http://dx.doi.org/10.1007/s10340-007-0189-2

[15] Álvarez Colom, O., Salvatore, A., Willink, E., Ordóñez, R., Isla, M.I., Neske, A. and Bardón, A. (2010) Insecticidal, Mutagenic and Genotoxic Evaluation of Annonaceous Acetogenins. Natural Product Communications, 5, 391-394.

[16] Di Toto Blessing, L., Álvarez Colom, O., Popich, S., Neske, A. and Bardón, A. (2010) Antifeedant and Toxic Effects of Acetogenins from Annona montana on Spodoptera frugiperda. Journal of Pest Science, 83, 307-310. http://dx.doi.org/10.1007/s10340-010-0299-0

[17] Tolosa, D., Álvarez Colom, O., Bardón, A. and Neske, A. (2012) Insecticidal Effects of Annonaceous Acetogenins from Rollinia occidentalis Seeds Extract on Spodoptera frugiperda. Natural Product Communications, 7, 1645-1646.

[18] Tolosa, D., Ruiz Hidalgo, J., Sal, P.E., Popich, S., Bardón, A. and Neske, A. (2014) Insecticidal Effects of the Annonaceous Acetogenin Squamocin and the Acetogenin Fraction of Seeds of Rollinia occidentalis on Soybean and Corn Pests. Journal of Agricultural Chemistry and Environment, 3, 156-160. http://dx.doi.org/10.4236/jacen.2014.34019

[19] McCloud, T.G., Smith, D.L., Chang, C.J. and Cassady, J.M. (1987) Annonacin, a Novel, Biologically Active Polyketide from Annona densicoma. Experientia, 43, 947-949. http://dx.doi.org/10.1007/BF01951681

[20] Pettit, G.R., Riensen, R., Leet, J.E., Polonsky, J., Smith, C.R., Schmidt, J.M., Dufresne, C., Schaufelberger, D. and Moretti, C. (1989) Isolation and Structure of Rolliniastatin-2, a New Cell Growth Inhibitory Acetogenin from Rollinia mucosa. Heterocycles, 28, 213-217. http://dx.doi.org/10.3987/COM-88-S6

[21] Cortes, D., Myint, S. and Hocquemiller, R. (1991) Molvizarin and Motrilin: Two Novel Cytotoxic Bis-TetrahydroFuranic $\gamma$-Lactone Acetogenins from Annona cherimolia. Tetrahedron, 47, 8195-8202. http://dx.doi.org/10.1016/S0040-4020(01)91014-2

[22] Chahboune, N., Barrachina, I., Royo, I., Romero, V., Sáez, J., Tormo, J.R., De Pedro, N., Estornell, E., Zafra-Polo, M.C., Peláez, F. and Cortes, D. (2006) Guanaconetins, New Antitumoral Acetogenins, Mitochondrial Complex I and Tumor Cell Growth Inhibitors. Bioorganic of Medicinal Chemistry, 14, 1089-1094.

http://dx.doi.org/10.1016/j.bmc.2005.09.036 